\title{
Stability Study Test Terminology
}

National Cancer Institute

\section{Source}

National Cancer Institute. Stability Study Test Terminology. NCI Thesaurus. Code C96076.

Terminology developed to support Study Tests within the Stability Data Standards. 